\title{
REVISTAMATEERIA
}

\section{Produção de revestimento cerâmico semi-poroso com adição de chamote de telhas}

\author{
Production of semi-porous ceramic tiles with \\ the addition of roof tile chamotte
}

Castro, R. J. S., Soares, R. A. L., Nascimento, R. M.

Programa de Pós-graduação em Ciência e Engenharia de Materiais.

PPgCEM/UFRN - Av. Senador Salgado filho,3000,CEP:59078-970.Natal,RN

e-mail: rjcastro33@hotmail.com ; arruda-soares@uol.com ; rmaribondo@ufrnet.br

\section{RESUMO}

A indústria de cerâmica vermelha é em parte responsável pela degradação ambiental provocadas pelo jazimento das matérias primas, a queima dos produtos e o descarte dos resíduos cerâmicos após queima. Este trabalho tem como objetivo verificar a potencialidade de se produzir revestimento cerâmico, incorporando chamote de telhas a uma massa básica típica para produção de revestimento semi-poroso. A massa básica e o chamote foram caracterizados por fluorescência de raios $\mathrm{X}$, análise mineralógica por difração de raios X. Corpos de prova foram confeccionados por prensagem uniaxial partir da massa básica aditivada com 5\%, $10 \%, 15 \%$ e $20 \%$ de chamote, em seguida queimados em escala industrial em forno de rolo, com temperatura de pico a $1135^{\circ} \mathrm{C}$ em um ciclo de $25 \mathrm{~min}$, para depois serem avaliados do ponto de vista tecnológico: absorção de água, retração linear de queima, tensão de ruptura a flexão, porosidade aparente, massa específica aparente, perda ao fogo e por último analisados microestruturalmente por microscopia eletrônica de varredura. Os resultados encontrados mostraram que a adição de chamote de telhas provoca redução da resistência mecânica e aumento de absorção de água. Mesmo assim, os resultados encontrados para a formulação dopada com até $20 \%$ de chamote encontram-se dentro dos valores estabelecidos pela norma vigente.

Palavras-chave: Resíduo de telha (Chamote); reaproveitamento; revestimento semi-poroso.

\section{ABSTRACT}

The red ceramics industry is partially accountable for the environmental degradation provoked by extraction of raw material, burning of the products and discards of waste ceramic after burning. This paper aims at examining the potential of the production of ceramic tiles by adding roof tile chamotte to the basic mass typically used in the production of semi-porous tiles. The basic mass and the chamotte were characterized by $\mathrm{X}$ ray fluorescence, mineralogical analysis by $\mathrm{X}$ ray diffraction. Test samples were produced by uniaxial pressing with the addition of $5 \%, 10 \%, 15 \%$ and $20 \%$ chamotte to the basic mass, being then fired in an industrial roller oven with a peak temperature of $1135^{\circ} \mathrm{C}$ in a cycle of $25 \mathrm{~min}$, to be later analyzed from a technological point of view: water absorption, linear retraction, flexural strength, apparent porosity, apparent specific mass and burning loss, being finally microstructurally analyzed through scanning electron microscopy The results have shown that the addition of roof tile chamotte causes a reduction in the mechanical strength and increases water absorption. Yet, the results found for the formulation doped with up to $20 \%$ chamotte are within the range established by current regulations.

Keywords: Roof tile waste (chamotte); reuse; semi-porous ceramic tiles. 


\section{INTRODUÇÃO}

Ao longo de sua existência, o homem sempre utilizou os recursos naturais do planeta e gerou resíduos com pouca ou nenhuma preocupação, já os recursos eram abundantes e a natureza aceitava passivamente os despejos realizados. A partir do século XVIII, com o surgimento da "onda" industrial, o modelo ou estratégia de desenvolvimento das nações consolidou duas bases técnicas e sociais. O objetivo principal era o crescimento econômico a curto prazo,mediante a utilização de novos processos produtivos e a exploração intensiva de energia e matérias primas,cujas fontes eram considerada limitadas. Este modelo gerou excedentes impressionantes de riqueza econômica, mas trouxe consigo grandes problemas sociais e ambientais, entre eles os resíduos [1].

A crescente evolução industrial traz consigo a elevada geração de resíduos, infelizmente as indústrias não tem se preocupado o suficiente com a destinação adequada dos mesmos, mas as questões referentes ao meio ambiente cada vez mais estão se tornando populares entre a sociedade, governo e indústria [2].

A reciclagem de resíduos industriais em materiais cerâmicos para fins diversos deve necessariamente ser acompanhada de uma avaliação dos problemas ambientais que este processo pode acarretar. Os resíduos são classificados em função de seus riscos potenciais ao meio ambiente, à saúde pública, de forma que eles possam ter manuseio e destinos adequados. A periculosidade de um resíduo é em função de suas propriedades físicas e químicas ou infecto-contagiosas que possa apresentar. Neste contexto, massas cerâmicas que contendo resíduo estão obrigatoriamente sujeitas à legislação ambiental, na qual é imperativa a análise do impacto ambiental causado pela incorporação do resíduo. Um resíduo que é totalmente incorporado na forma de produto final a um volume inerte de material perde sua identidade como resíduo [3].

A maioria das indústrias de cerâmica vermelha gera um volume considerado de resíduo de telhas, isto em função da má queima quebras realizadas durante o processo fabril e durante o armazenamento. Segundo dados das indústrias ceramistas algumas indústrias tem um controle rigoroso sobre seus resíduos, tendo um desperdício próximo a $1 \%$, enquanto que outras chegam a perto de $10 \%$ o que representa em função do grande volume de telhas produzidas no Brasil um grande volume de resíduo [4].

O aproveitamento dos rejeitos industriais para uso como materiais alternativos não são novos e têm dado certo em vários países desenvolvidos, sendo três as principais razões que motivam os países a reciclarem seus rejeitos industriais: primeiro, o esgotamento das reservas de matérias-primas confiáveis; segundo, os crescentes volumes de resíduos sólidos, que põem em risco a saúde pública, ocupam o espaço e degradam os recursos naturais e, terceiro, a necessidade de compensar o desequilíbrio provocado pelas altas do petróleo [5].

Algumas análises nas diversas áreas de fabricação indicaram um retorno financeiro e ambiental extraordinário com o reuso de resíduos. Diversos projetos já foram e serão desenvolvidos na busca incessante da preservação ambiental e na diminuição dos custos industriais. A maioria das indústrias não está consciente da importância e da quantidade desperdiçada em seus processos produtivos em cada minuto de produção. Os resultados obtidos com esses processos de reuso demonstram as reais formas de redução de custo e impactos ambientais e comparativos dos investimentos com o retorno financeiro da implantação que provocam a mudança na conscientização industrial, além do aumento de credibilidade e imagem da empresa perante o mercado consumidor [6].

O resíduo de telha é inerte, mas o descarte deste produto as margens de estradas, as margens dos rios e diretamente a céu aberto gera um impacto ambiental negativo [7].

Os fatos citados e por si justificam um estudo que venha a utilizar de forma racional o resíduo de telha, por conseguinte este trabalho visa a adição de chamote de telhas para produção de revestimento semi-poroso alternativo. 


\section{MATERIAIS E MÉTODOS}

Para realizar o estudo de obtenção do semi-poroso alternativo, foi utilizada a massa básica coletada no cilo de uma indústria e o resíduo de telhas resultantes de más queimas, ou outros problemas que impossibilitavam o uso convencional das mesmas. O resíduo foi submetido a moagem em moinho de bolas por $1 \mathrm{~h}$ com rotação de $210 \mathrm{rpm}$, e depois passado na peneira $\mathrm{ABNT}^{\circ} 40$.

A análise granulométrica das matérias primas foi realizada por difração a lazer utilizando-se um granulômetro modelo 920L do fabricante CILAS, auxiliado com o programa The Particle Expert.

A composição química das matérias primas foi determinada por fluorescência de raios X (FRX) para isso, utilizou-se o equipamento espectrômetro da marca Shimadzu, modelo EDX-720. Para realizar as análises utilizou-se o método semi-quantitativo, numa atmosfera de vácuo. Os resultados obtidos são apresentados na forma dos óxidos mais estáveis dos elementos químicos presentes. A análise mineralógica das matérias primas, bem como as fases formadas após a queima dos corpos de prova, foi obtida por ensaios de DRX. O equipamento é um XRD-6000 Shimadzu com tubo de Cu ( = 1,54056 A). A tensão utilizada foi de $40 \mathrm{kV}$ e a corrente foi de $30 \mathrm{~mA}$, com varredura de $5^{\circ}$ a $80^{\circ}$ para 2 , com velocidade de $2^{\circ} / \mathrm{min}$ e passo de $0,02 \%$ passo. A avaliação das fases de cada matéria-prima foi dada por comparação entre os picos gerados no difratograma com cartas padrões do programa de computador JCPDF, cadastradas no ICDD (Internacional Center for Difraction Data).

Após a secagem das matérias primas, as formulações foram obtidas por diferentes combinações das proporções da massa básica com resíduo dando origem as formulações, conforme mostra a Tabela 1:

Tabela 1: Composições das massas cerâmicas em percentual das matérias primas.

\begin{tabular}{c|c|c}
\hline FORMULAÇÕES & $\begin{array}{c}\text { MASSA } \\
\text { BÁSICA }\end{array}$ & CHAMOTE \\
\hline MB & $100 \%$ de MB & $0,0 \%$ \\
\hline F5 & $95 \%$ de MB & $5,0 \%$ \\
\hline F10 & $90 \%$ de MB & $10,0 \%$ \\
\hline F15 & $85 \%$ de MB & $15,0 \%$ \\
\hline F20 & $80 \%$ de MB & $20,0 \%$ \\
\hline \multicolumn{2}{|l}{}
\end{tabular}

Em seguida se adicionou água em cada formulação até atingir o percentual de $10 \%$ de umidade. As formulações então foram homogeneizadas e peneiradas em malha 20 com o objetivo de transformar em pequenos aglomerados. Depois da granulação, as formulações foram armazenadas em sacos plásticos vedados, para que não houvesse perda de umidade.

Após 24h de descanso da massa com o intuito de melhorar a reologia foram conformados os corpos de prova por prensagem uniaxial sob uma pressão de $25 \mathrm{MPa}$, utilizando-se cerca de $15 \mathrm{~g}$ de cada mistura obtendo-se peças em formato de paralelepípedo nas dimensões 60,0 × 20,0 × 5,0 mm. Após a obtenção dos corpos de prova, estes foram submetidos à secagem em secador industrial de planos paralelos da marca ICOM, e cujo ciclo de secagem é controlado e temperatura variando da ambiente a $350^{\circ} \mathrm{C}$ com duração de 12 min. A etapa de queima foi realizada com ciclo de queima rápida de $25 \mathrm{~min} \mathrm{em}$ forno industrial contínuo de rolo da marca ICOM, a temperatura de queima foi de $1135^{\circ} \mathrm{C}$ de pico. Os corpos de prova queimados foram avaliados em suas propriedades tecnológicas de retração linear (RL), absorção de água (AA) e tensão de ruptura à flexão em três pontos (TRF). A análise microestrutural foi realizada a partir da avaliação da textura do material por microscópio eletrônico de varredura (MEV) modelo SSX-550 de marca Shimadzu, sem nenhum tratamento prévio de lixamento ou polimento. Porém, as amostra foram metalizadas para tornaremse condutoras, e aderidas a um porta amostra de alumínio, por uma fita condutora de carbono. 


\section{RESULTADOS E DISCUSSÃO}

\subsection{Análise granulométrica por difração a lazer}

Na Figura 1 que representa a distribuição granulométrica das matérias primas, o que pode ser observado é que a massa básica apresenta uma granulometria mais fina, em que todas as partículas apresentam diâmetro inferior a $35 \mu \mathrm{m}$ e diâmetro médio de $6,54 \mu \mathrm{m}$. o que pode trazer a massa uma melhoria na cinética de sinterização, aumentar a resistência mecânica dos corpos a verde, já o chamote apresenta uma granulometria maior com diâmetro médio de $8,32 \mu \mathrm{m}$ o que pode favorecer um melhor empacotamento dos partícula das formulações, reduzir a retração de secagem e minimizar os efeitos deletérios produzidos durante o processo de secagem [8].

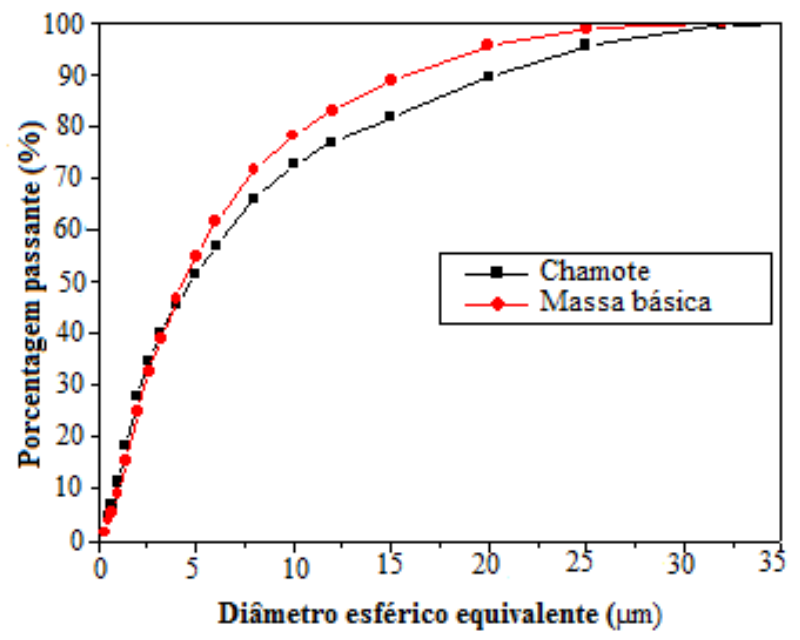

Figura 1: distribuição granulométrica das matérias primas.

\subsection{Análise química por fluorescência de raios $\mathrm{x}$ (frx)}

Conforme composição química apresentada na Tabela 2 observa-se que a massa básica tem predominância de óxido de silício $(50,9 \%)$ e alumínio $(24,8 \%)$ e baixo teor de $\mathrm{CaO}(0,4 \%)$ o que a caracteriza como não carbonática, apresenta alto teor de óxido de ferro $(10,1 \%)$ que em linhas gerais é responsável pela coloração vermelha após queima, além de reduzir a refratariedade da massa. $\mathrm{O}$ teor de 6,6\% de potássio mostra que a massa básica é composta por argilas fundentes que sinterizam em menor temperatura. $\mathrm{O}$ chamote de telha utilizado apresentou elevada concentração de $\mathrm{SiO}_{2}(62,5 \%), \mathrm{Al}_{2} \mathrm{O}_{3}(21,3 \%)$ e $\mathrm{Fe}_{2} \mathrm{O}_{3}(8,5 \%)$ devido a natureza argilosa das matérias-primas na produção de telhas. Os álcalis $\mathrm{K}_{2} \mathrm{O}, \mathrm{Na}_{2} \mathrm{O}, \mathrm{MgO}$ e $\mathrm{CaO}$, apareceram em menor concentração comparada a massa básica, além de uma menor perda ao fogo que se deve ao fato do chamote ser um material queimado uma temperatura em torno de $900^{\circ} \mathrm{C}$, onde já ocorreu a combustão da matéria orgânica, perda das hidroxilas, decomposição dos carbonatos e fusão parcial dos álcalis. 
Tabela 2: Composição química das matérias primas.

\begin{tabular}{c|c|c}
\hline \multicolumn{3}{c}{ CONCENTRAÇÃO EM MASSA (\%) } \\
\hline $\begin{array}{c}\text { ÓXIDOS } \\
\text { PRESENTES }\end{array}$ & $\begin{array}{c}\text { MASSA } \\
\text { BÁSICA }\end{array}$ & CHAMOTE \\
\hline $\mathrm{SiO}_{2}$ & 50,9 & 62,5 \\
\hline $\mathrm{Al}_{2} \mathbf{O}_{2}$ & 24,8 & 21,3 \\
\hline $\mathrm{Fe}_{2} \mathbf{O}_{2}$ & 10,1 & 8,5 \\
\hline $\mathbf{K}_{2} \mathbf{O}_{2}$ & 6,6 & 4,1 \\
\hline $\mathrm{TiO}_{2}$ & 1,1 & 1,5 \\
\hline $\mathbf{C a O}$ & 0,4 & 0,9 \\
\hline $\mathbf{M g O}$ & 1,7 & 0,6 \\
\hline $\mathbf{P F}$ & 4,4 & 0,6 \\
\hline
\end{tabular}

\subsection{Análise Mineralógica por difração de raios x (drx)}

De acordo com a análise mineralógica verificada nas Figuras 2 e 3 a massa básica (Figura 2) apresentou quatro fases cristalinas a ilita $\left[\left(\mathrm{K}, \mathrm{H}_{3} \mathrm{O}\right) \mathrm{Al}_{2} \mathrm{Si}_{3} \mathrm{Al}_{10}(\mathrm{OH})_{2}\right]$, quartzo $\left(\mathrm{SiO}_{2}\right)$, ortoclásio $\left[\mathrm{K}(\mathrm{Al}, \mathrm{Fe}) \mathrm{Si}_{2} \mathrm{O}_{8}\right]$ e a vermiculita $\left[(\mathrm{Mg}, \mathrm{Al})_{3}(\mathrm{Al}, \mathrm{Si})_{4} \mathrm{O}_{10}(\mathrm{OH})_{2} \cdot 4 \mathrm{H}_{2} \mathrm{O}\right]$. A argila ilítica é largamente utilizada na produção de revestimento de base vermelha. É uma argila fundente, pois é fonte de potássio, principal agente de sinterização da massa cerâmica. Além disso, verificou-se a presença do feldspato potássico, o ortoclásio. A fase cristalina vermiculita é justificada pela presença do $\mathrm{MgO}$ detectado na fluorescência de raios X. A vermiculita é um mineral semelhante à mica, formado essencialmente por silicatos hidratados de alumínio e magnésio que sofre expansão quando em presença de água ou quando submetida à alta temperatura. A presença do quartzo na massa melhora o processo de secagem, a liberação de gases na queima e minimiza a retração, além de desempenhar um importante papel na microestrutura da peça cerâmica.

$\mathrm{O}$ chamote de telha (Figura 3) apresentou cinco fases, a ilita $\left[\left(\mathrm{K}, \mathrm{H}_{3} \mathrm{O}\right) \mathrm{Al}_{2} \mathrm{Si}_{3} \mathrm{Al}_{10}(\mathrm{OH})_{2}\right]$, quartzo $\left(\mathrm{SiO}_{2}\right)$, hematita $\left(\mathrm{Fe}_{2} \mathrm{O}_{3}\right)$, albita $\left(\mathrm{NaAlSi}_{3} \mathrm{O}_{8}\right)$ e dolomita $\mathrm{CaMg}\left(\mathrm{CO}_{3}\right)_{2}$, a presença de hematita se deve a processos geológicos ou por se tratar de um material queimado a temperatura superior a $900^{\circ} \mathrm{C}$, os traços de ilita deve-se a temperatura de queima das telhas terem sido inferior a perda da estrutura cristalina da ilita geralmente em torno $940^{\circ} \mathrm{C}$ [9].

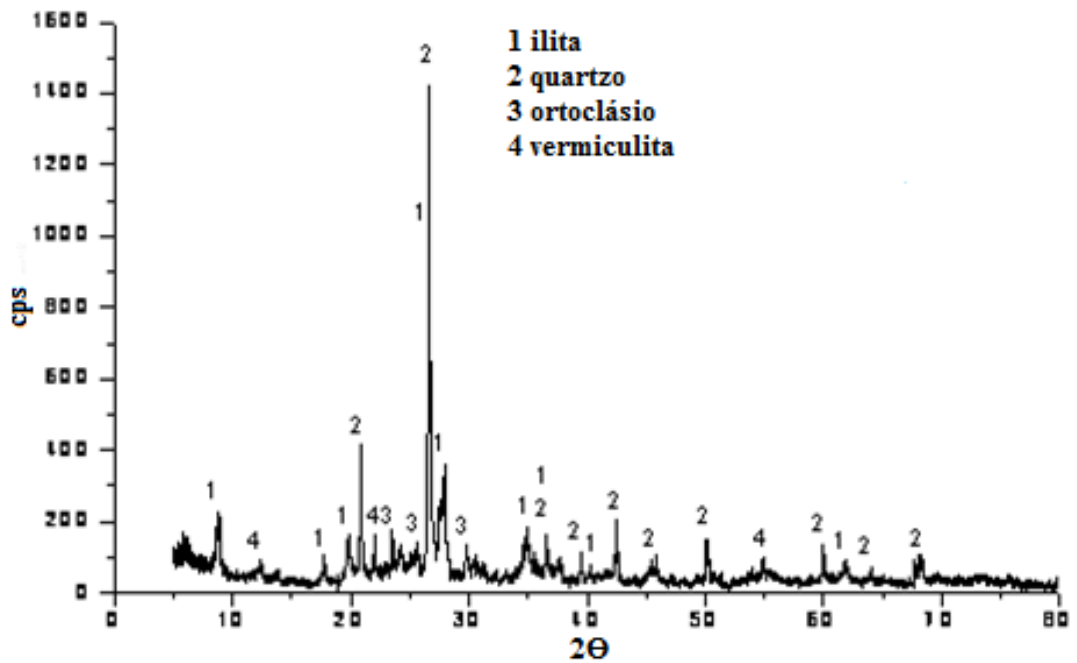

Figura 2: Difratograma de raios $\mathrm{X}$ da massa básica. 


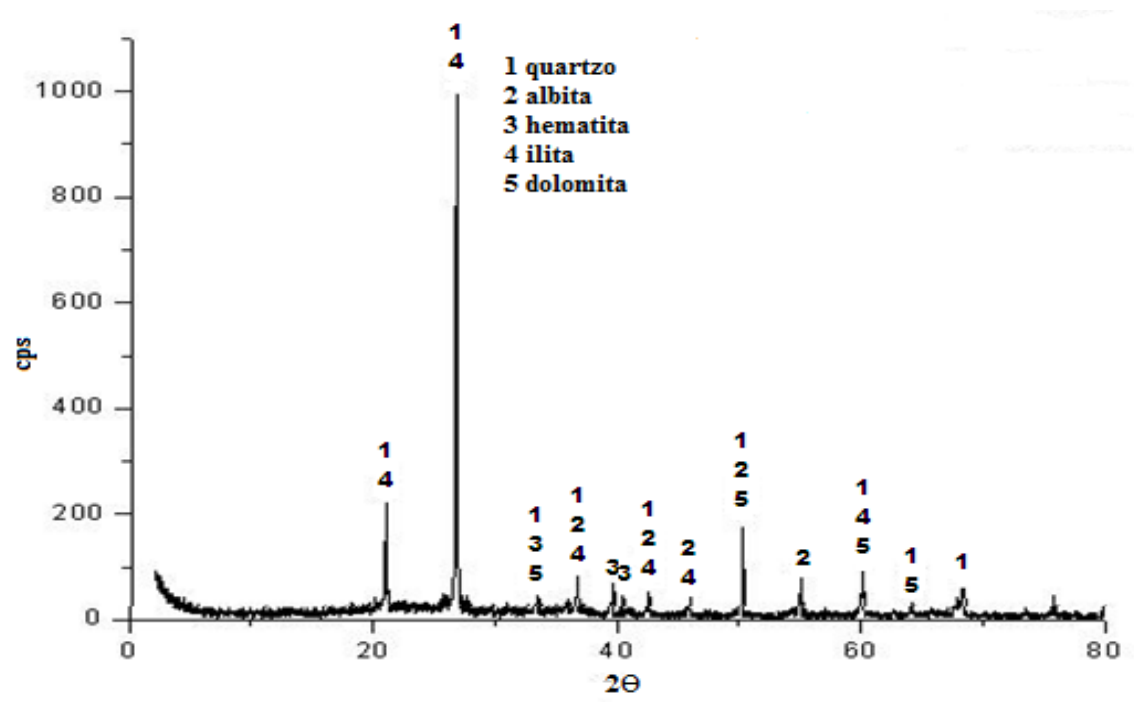

Figura 3: Difratograma de raios $\mathrm{X}$ do chamote.

\subsection{Análise das propriedades tecnológicas}

Os resultados apresentados na Figura 4 mostram que à medida que aumenta-se o teor de chamote a massa básica, tem-se um aumento na absorção de água e respectiva redução de resistência mecânica, que está atribuída ao menor grau de sinterização já que uma granulometria mais grosseira reduz a cinética de sinterização, tornando o material mais poroso, propenso à absorção de água e a redução da resistência mecânica. Já a retração linear permaneceu inalterada à medida em que se aumentou o teor de chamote, isto se deve ao fato do chamote se tornar um material inerte a esta temperatura de estudo.

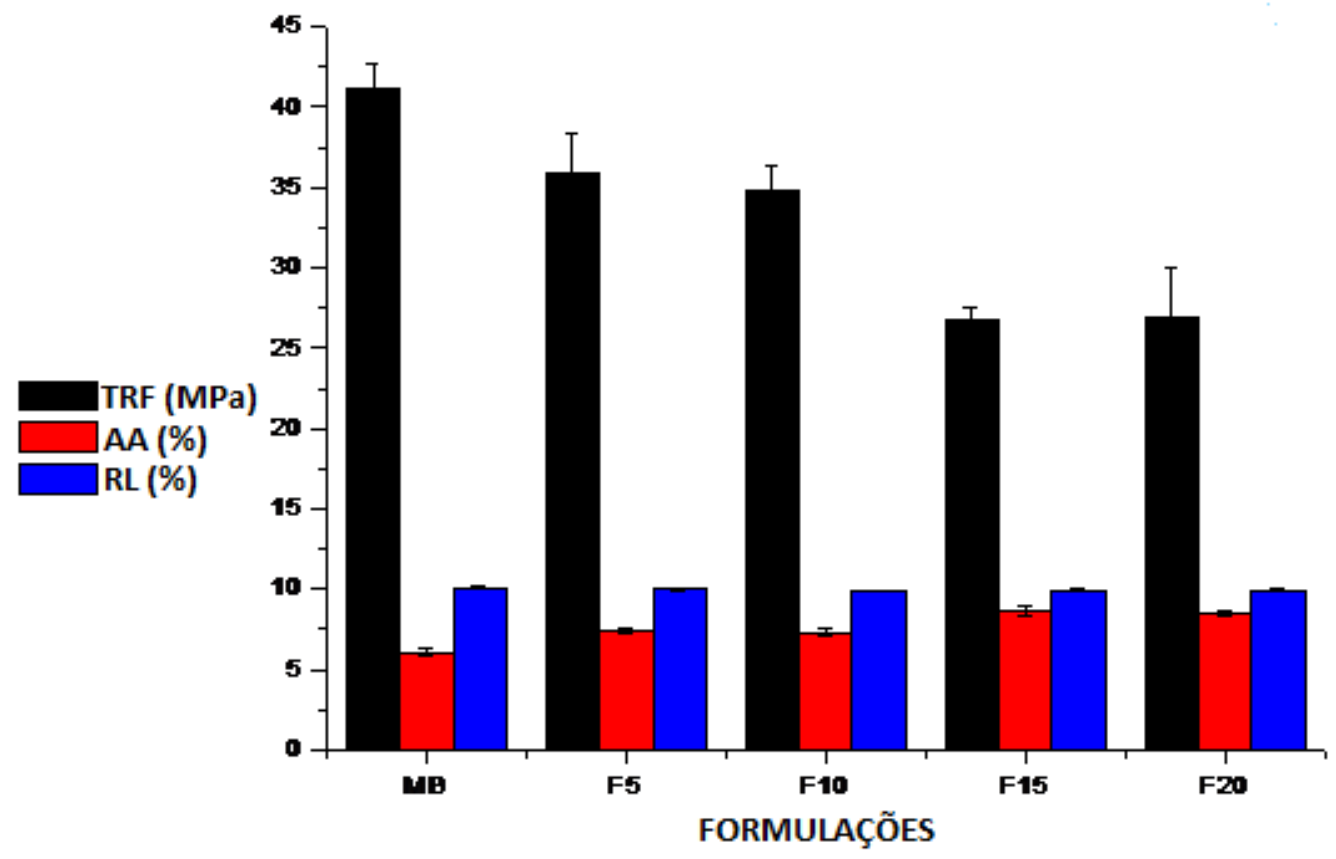

Figura 4: Resistência mecânica, absorção de água e retração linear de queima dos corpos queimados.

O que é verificado na Figura 5 é que á medida em que aumenta-se o teor de chamote a massa básica a MEA diminuiu progressivamente ao passo que a porosidade aparente aumentou, esta redução da densificação do material está relacionada ao comportamento das partículas de chamote nesta temperatura em estudo já o aumento da porosidade está associado a granulometria e a forma inerte como o chamote se comportou. A redução de perda ao fogo se deve ao chamote ser um material mais estável em que toda matéria orgânica já 
foi calcinada, e os carbonatos completaram sua decomposição.

Conforme a Norma NBR 13.817/1997 [10], baseada na ISO 13.006/1995 [11], que classifica os revestimentos cerâmicos de acordo com sua absorção de água em revestimento cerâmico do tipo semi-poroso, cuja $6 \%$ < absorção de água $\leq 10 \%$ e a NBR 13.818/1997 [12], que estipula a TRF $\geq 18 \mathrm{MPa}$, todas as formulações estão dentro destes parâmetros.

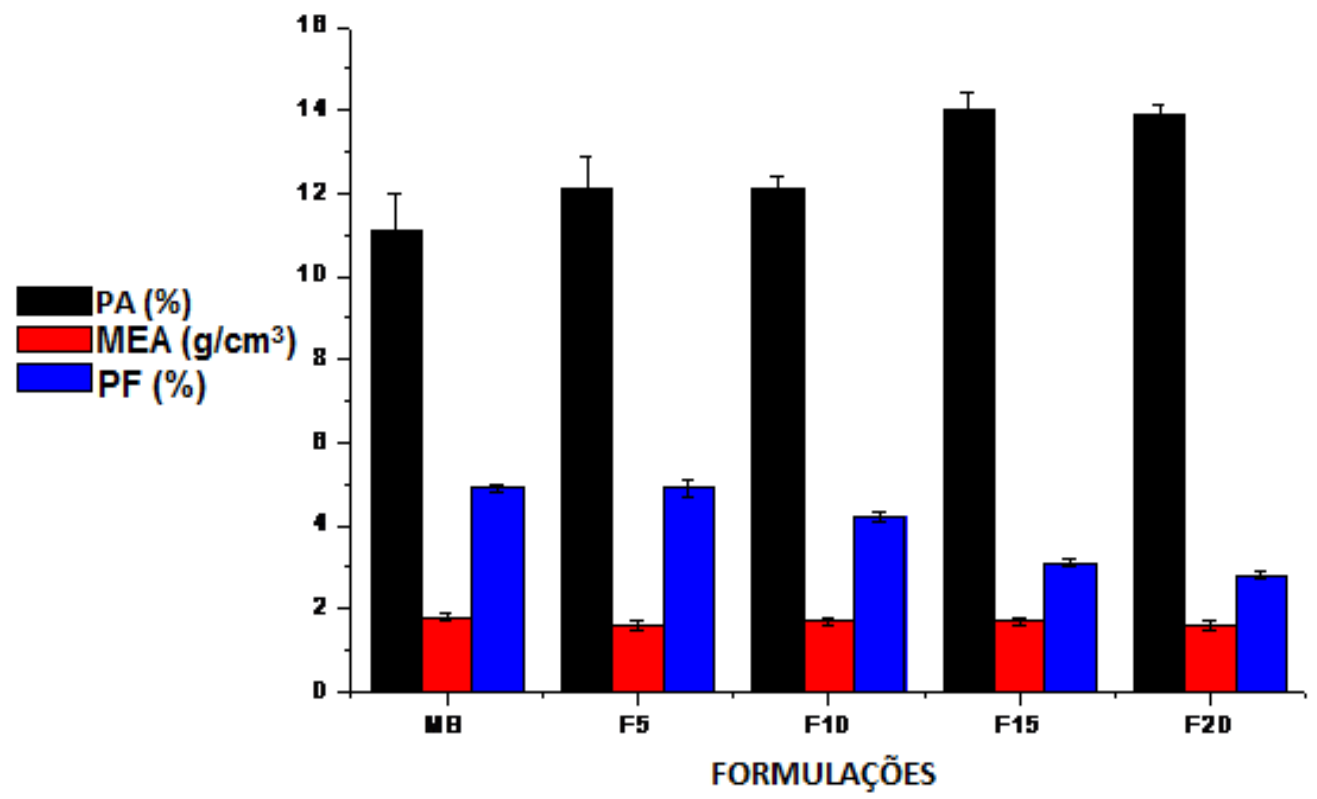

Figura 5: Porosidade aparente, massa específica aparente e perda ao fogo dos corpos queimados.

\subsection{Análise microestrutural por microscopia eletrônica de varredura (mev)}

Com relação á análise microestrutural foi possível visualizar na amostra da massa básica (Figura 6) a presença de superfície menos rugosa que a das amostras das formulações F5 ou F20 (Figuras 7 e 8). Isso se deve ao fato da amostra sem chamote apresentar maior teor de fundentes, o que proporciona maior quantidade de fase líquida durante o processo de sinterização. Observa-se também que a amostra da formulação F20 apresenta maior quantidade de poros abertos que a amostra da formulação F5 isto vem a justiçar o aumento da absorção de água e a redução da resistência mecânica, que também é contribuída pela própria natureza do processo de queima das peças, pois foram queimadas em um ciclo de queima rápida em um forno a rolo o que em presença elevada de ferro contribui de maneira negativa para melhoria das propriedades tecnológicas [13]. 


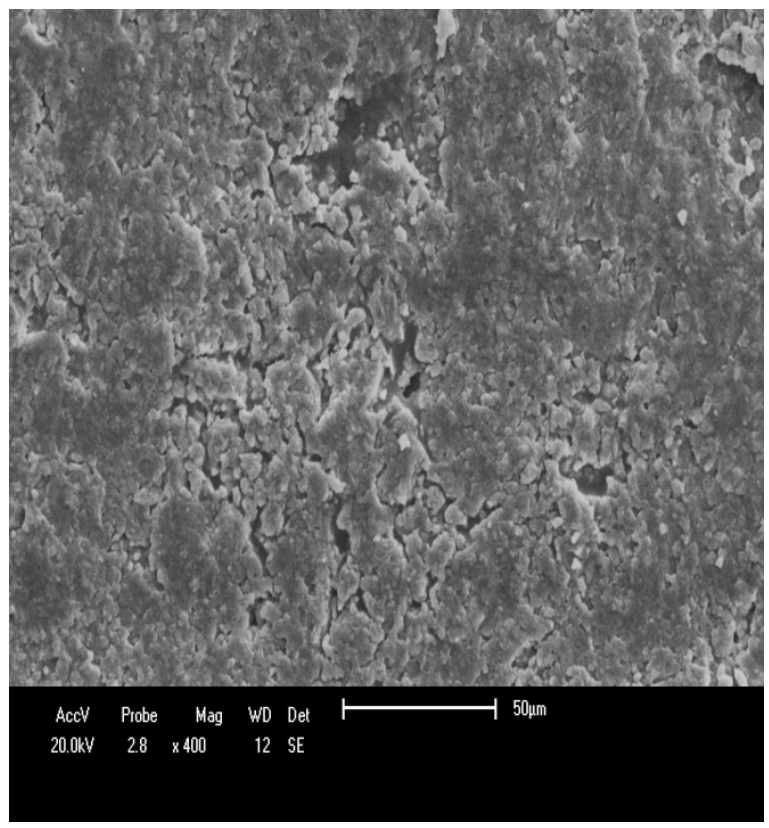

Figura 6: Micrografia do corpo de prova preparado a partir da massa básica ampliado 400 vezes.

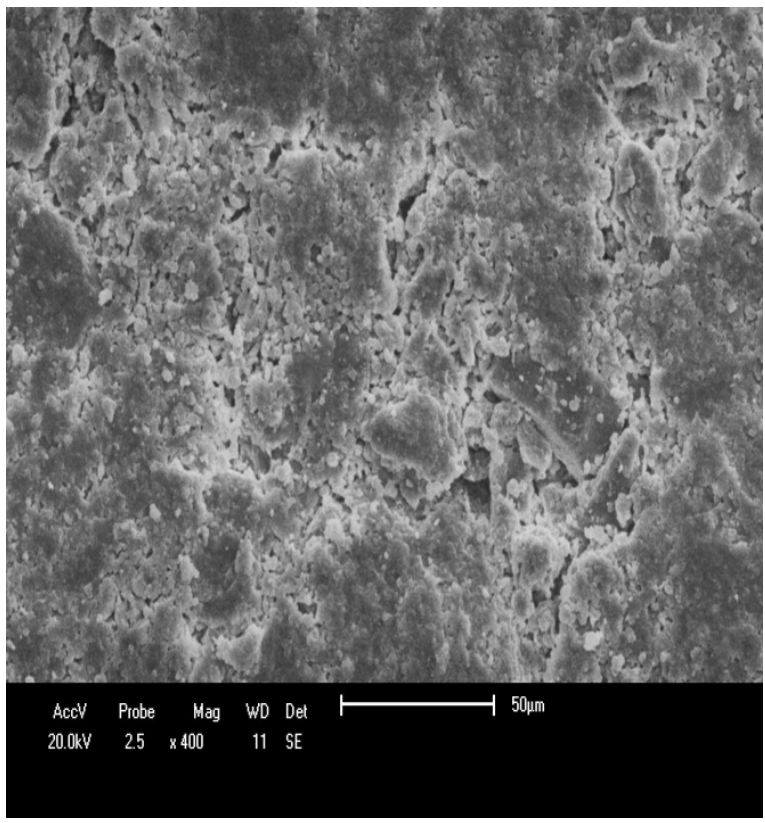

Figura 7: Micrografia do corpo de prova preparado a partir da formulação F5 ampliado 400 vezes. 


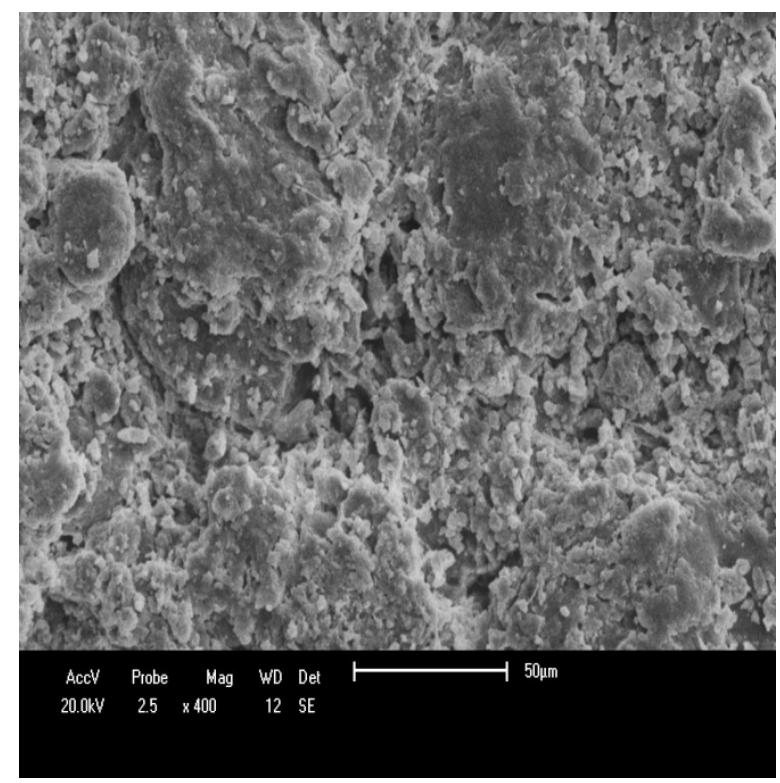

Figura 8: Micrografia do corpo de prova preparado a partir da formulação F20 ampliado 400 vezes.

\section{CONCLUSÕES}

As análises microscópicas e das propriedades tecnológicas mostraram que com o aumento do teor de chamote na massa cerâmica melhorou a estabilidade dimensional das peças, mas concomitantemente aumentou a porosidade e reduziu a resistência mecânica. Esta ocorrência se verificou devido a baixa reatividade do chamote com os demais componentes da massa cerâmica promovida pelo ciclo térmico aplicado no forno indústrial. Outro fator de implicância é o menor teor de fundentes presentes no chamote, como mostraram as análises química e mineralógica. Porém todas as formulações estudadas com até $20 \%$ de chamote apresentaram os valores de absorção de água e tensão de ruptura à flexão dentro dos parâmetros estabelecidos pelas normas vigentes para revestimento semi-poroso.

Desta forma, os resultados das análises obtidas na presente pesquisa apontaram uma potencialidade da aplicação do chamote de telha finamente moído em formulações de massa cerâmica de revestimento semiporoso, configurando-se como uma matéria prima alternativa viável, ao mesmo tempo em que possibilita um ganho ambiental com seu aproveitamento ao invés do seu descarte direto ao meio ambiente.

\section{AGRADECIMENTOS}

Os autores agradecem ao grupo MURANO, SENAI-Pi,UFPI e ao IFPI.

\section{BIBLIOGRAFIA}

[1] MODESTO, C., BRISTOT, V., MENEGALI, G., et al. “Obtenção e caracterização de materiais cerâmicos a partir de residuos sólidos industriais”, Cerâmica Industrial, v8, pp. 14-18, jun/ago. 2003.

[2] GUNGOR, A. G.,'Issues in environmentally conscious manufacturing and product recovery a survey", Computers \& Industrial Engineering, v36, n. 1, pp. 811-853, Feb. 1999.

[3] CEPRO - Fundação Centro de Pesquisas Econômicas e Sociais do Piauí. Diagnóstico e diretrizes para o setor mineral do estado do Piauí. Teresina, 2005.

[4] FERNANDES P. F., "Reaproveitamento do lodo da estação de tratamento de tratamento de efluentes de uma indústria cerâmica”, M.Sc ., UFSC, SC, Brasil, 2002. 
[5] SOARES, R. A. L., CASTRO, R. J. S., NASCIMENTO, R. M. et al., "Influência do Teor de Calcário no Comportamento Físico, Mecânico e Microestrutural de Cerâmicas Estruturais" Cerâmica Industrial, v. 15, n. 2, pp. 41-45, março/abril. 2010.

[6] MENEZES R. R., FERREIRA H. S., NEVES G. de A., et al, "Uso de rejeitos de granitos como matériaprima cerâmicas", Cerâmica, v.48 (306) Abr/Mai/Jun, 2002.

[7] BRASIL. Lei $\mathrm{n}^{\circ}$ 12.305, artigo 47, de 02 de agosto de 2010. http://www.planalto.gov.br/ccivil_03/_ato2007-2010/2010/lei/112305.htm

[8] JORDÃO, M. A. P., "Curso Internacional de treinamento em grupo em tecnologia cerâmica", 199 Cerâmica Branca”, IPT/JICA, São Paulo,1995.

[9] SANTOS P. S., Ciência e tecnologia de Argilas, 1edição, São Paulo, Edgard Blücher-LTDA, 1989.

[10] NBR 13817. "Placas cerâmicas para revestimento - Classificação", 1997.

[11] ISO 13006. "Ceramic tiles-Definitions, classification, characteristics and marking", 1998.

[12] NBR 13818. "Placas cerâmicas para revestimento - Especificação e métodos de ensaios", 1997.

[13] DUTRA, R.P., "Efeito da velocidade de aquecimento nas propriedades de produtos da cerâmica estrutural”, D.Sc., PPgCEM/UFRN, Natal, RN, Brasil, 2007. 